\title{
Muscarinic Acetylcholine Receptor M1
}

National Cancer Institute

\section{Source}

National Cancer Institute. Muscarinic Acetylcholine Receptor M1. NCI Thesaurus. Code C20965.

Muscarinic acetylcholine receptor M1 (460 aa, 51 kDa) is encoded by the human

CHRM1 gene. This protein is involved in synaptic transmisssion and G protein-coupled receptor signaling. 